\title{
BSDHT - On a mission
}

\section{By Helen Minnery, Immediate Past President BSDHT, Liverpool, UK}

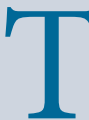
he British Society of Dental Hygiene and Therapy (BSDHT) started out life as the British Dental Hygienists' Association back in 1949 and this year celebrates 70 years as an organisation. In the last 70 years it has seen 23 Presidents, with me being the 24th. During this time the organisation has undergone many transformations and witnessed many changes in the profession, for which the BSDHT has been the driving force behind many - but its ethos has always remained the same.

The BSDHT is here to represent the interests of its members at a national level within the profession and in the political arena. Looking back at the changes over the past 70 years, we have been able to start working to our full scope without a dentist on the premises. Hygienists now provide local anaesthetic, temporary fillings, can recement crowns and, in 2013, saw the introduction of direct access. But further changes are needed to adapt to our modern roles and the BSDHT is once again keen to stand up for the profession and drive things forwards. The most recent example of this is our joint project with the British Association of Dental Therapy (BADT). We are campaigning for exemptions to the Medicines Act that will enable dental hygienists and dental therapists to administer certain medications that patients need without a prescription from the dentist.

The BSDHT as an organisation is very much a team effort, utilising various individual skills and expertise. As it stands today we have our own office, administration team, executive team and four directors, but we also seek help and support in certain areas from our members who have a vast wealth of knowledge and experience. Being President doesn't mean you know everything! We are a network of like-minded dental hygienists and dental therapists who strive every day to provide the very best standards of care to all our patients. It was, and will always be, our mission to keep adding to the benefits available to members and to fight for the changes that dental hygienists and dental therapists need to do their jobs to the best of their abilities.

It was an absolute delight and honour to be President of the BSDHT from 2016-2018. Having been a member of the society since qualifying in 1992, I have always been passionate about the profession and the society. The role of the President has changed vastly over the past 70 years as the Society has grown from its original 12 members in 1949 to around 3,500 today (including student members). The President is the face of the organisation, representing the profession at national and international levels to organisations such as the GDC, parliamentary groups, Department of Health and the International Federation of Dental Hygiene. As President, I was able to share my own experience and, combined with the expertise of the executive team around me, could help to continue to steer the Society in the right direction.

The BSDHT is very much dedicated to its members. We are proud to offer an array of benefits as part of our membership that range from CPD opportunities to indemnity cover. Our regional study days cover a wide variety of relevant topics and our annual Oral Health Conference and Exhibition while I was President, is the general lack have, the bigger voice we have in the political arenas when representing the profession. and dental therapists. So, if you strive for encourage you to join a professional body as (OHC) is the highlight of our educational calendar. One point that I would like to highlight, and which became apparent of understanding on the value of being a BSDHT member. The more members we

The more members we have, then the more funding we have to be able to go out there and strive for change. To enable the Society to do this there are costs involved, such as travel, accommodation and loss of earnings, as many of us are practising dental hygienists change and want your voice to be heard, I they are the people working for you. I have never looked back or questioned the value of my membership and being part of a team running the Society just reaffirms this.

the

BDA members get FREE access to our elibrary:

- access to over 350 dental ebooks

- download to PC or tablet

- print up to one chapter

- download as often as you like.

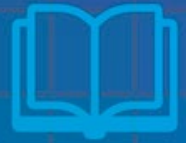

